\title{
A Novel Method for Eliminating Redundant Option Statements in the Graph Model for Conflict Resolution
}

\author{
Shinan Zhao ${ }^{1(\sqrt{(})}$ (1) and Haiyan $\mathrm{Xu}^{2}$ \\ ${ }^{1}$ School of Economics and Management, \\ Jiangsu University of Science and Technology, Zhenjiang 212003, China \\ zhugeliuyun1989@163.com \\ 2 College of Economics and Management, \\ Nanjing University of Aeronautics and Astronautics, Nanjing 211106, China
}

\begin{abstract}
The option prioritization is the most effective preference ranking approach within the framework of the graph model for conflict resolution, in which a set of option statements for each decision maker (DM) involved in a dispute is determined by individual judgments. Inevitably, some option statements may be unnecessary or redundant. To address the redundancy of option statements, a novel option statement reduction method as well as an effective reduction algorithm is developed in this research based on the rough set theory. Furthermore, the Elmira conflict is utilized to show how the proposed option statement reduction method can be employed for efficiently eliminating redundant option statements of DMs.
\end{abstract}

Keywords: Graph model for conflict resolution - Option statements · Redundancy $\cdot$ Preference ranking

\section{Introduction}

Conflicts are very pervasive in social, political, economic, environmental and other areas, where multiple stakeholders or decision makers (DMs) involved in a given dispute dynamically interact with each other for pursuing their own benefits. The graph model for conflict resolution (GMCR) is a very powerful and flexible methodology which can be employed for modeling and analyzing tough conflict situations [1-3]. In the modeling stage, the DMs, their options, feasible states and each DM's preference over states should be identified according to the background information about a particular conflict. The preference of DMs is very important in stability analysis but difficult to be determined due to the diversity of individual value systems. Three preference ranking methods were developed by Fang et al. $[4,5]$ within the framework of GMCR for conveniently acquiring DMs' preference over states: direct ranking, option weighting and option prioritization.

The most commonly used and effective technique for preference ranking in GMCR is option prioritization, in which each DM's preference over states can be reflected by a set of option statements consisting of some numbered options and connectives. Then 
the classical option prioritization approach was improved for handing strength of preference [6-8], unknown preference [9, 10], fuzzy preference [11-14], grey preference $[15,16]$, and probabilistic preference [17, 18]. Since the option statements are determined according to individual cognition and subjectivity, there may exist some unnecessary or redundant statements which should be removed for the sake of computing efficiency. Hence, a novel option statement reduction approach is proposed in this research for eliminating redundant option statements in option prioritization.

The organization of this paper is as follows. In Sect. 2, the option prioritization technique is briefly introduced within the GMCR paradigm. Subsequently, an option statement reduction method as well as its algorithm is purposefully developed in Sect. 3. In Sect. 4, the Elmira conflict is utilized for demonstrating the practicality of the proposed method. Finally, some conclusions and future work are presented in Sect. 5 .

\section{Option Prioritization in GMCR}

A conflict can be modeled as a graph model $G=\left\langle N, S,\left\{A_{i}, \succsim_{i}: i \in N\right\}\right\rangle$, where

(1) $N=\{1,2, \cdots, i, \cdots, n\}$ is the set of decision makers;

(2) $S=\left\{s_{1}, s_{2}, \cdots, s_{l}, \cdots, s_{m}\right\}$ is the set of feasible states;

(3) $A_{i}$ is the set of oriented arcs of DM $i \in N$, which contains all of the unilateral moves by DM $i$ in one step; and

(4) $\succsim_{i}$ stands for the preference relations (more or less preferred) over states by DM $i$.

Within the framework of GMCR, the option prioritization is the most convenient and effective technique for acquiring the preference of DMs involved in a dispute, in which a DM's preference over states can be reflected by a set of option statements composed of numbered options and several logical connectives such as "\& (and)", “- (not)", "I (or)", "IF" and "IFF (if and only if)". Furthermore, the option statements are presented from the most to least important in a hierarchical order.

Let $K=\left\{\Omega^{1}, \Omega^{2}, \cdots, \Omega^{l}, \cdots, \Omega^{k}\right\}$ be the set of option statements listed by priority for a given DM, in which $\Omega^{l}$ is the $l$ th option statement. In a particular state $s \in S$, each option statement $\Omega^{l}$ can be true (T) or false (F). Let the value of $\Omega^{l}$ be $\Omega^{l}(s)$. If $\Omega^{l}$ holds at state $s$, then $\Omega^{l}(s)=\mathrm{T}$; otherwise, $\Omega^{l}(s)=\mathrm{F}$.

The incremental score of the option statement $\Omega^{l}$ at state $s$ is written as

$$
\Psi_{l}(s)=\left\{\begin{array}{cc}
2^{k-l} & \text { if } \Omega_{l}(s)=\mathrm{T} \\
0 & \text { otherwise }
\end{array}\right.
$$

The total score of all of the option statements in $K$ at state $s$ is denoted by

$$
\Psi(s)=\sum_{l=1}^{k} \Psi_{l}(s)
$$


According to each state's score $\Psi(s)$, a DM's preference over states can be determined. More specifically, a state with a higher score is more preferred than a state with a lower score. And two states are equally preferred if their scores are the same.

As introduced above, a DM's preference over states can be easily obtained by using the option prioritization technique. However, some option statements may be redundant since all of the option statements are determined according to personal judgments. The redundancy of option statements which should be removed could increase the computational complexity of preference ranking, especially in large-scale conflicts. Hence, it is very important to develop an option statement reduction method for determining minimal option statement sets that do not change the preference ranking results. In the following, an attribute reduction method based on rough set theory [19, 20] is incorporated into the option prioritization within the GMCR paradigm for eliminating redundant or useless option statements.

\section{An Option Statement Reduction Method for Option Prioritization}

The objective of the option statement reduction method is to find minimal option statements sets which do not change the results of preference ranking. The basic idea is as follows:

\section{(1) Determine the universe, condition and decision attributes}

The feasible states, option statements, and the orders of states are regarded as universe (U), condition attributes (C) and decision attribute (D), respectively. Let $S=\left\{s_{1}, s_{2}, \cdots, s_{m}\right\}$ be the set of feasible states, $K=\left\{\Omega^{1}, \Omega^{2}, \cdots, \Omega^{l}, \cdots, \Omega^{k}\right\}$ be the set of option statements listed from the most important on the left to the least important on the right for a given DM, $D_{0}=\left\{d_{1}, d_{2}, \cdots, d_{m}\right\}$ be the order of ranked states, and $a_{i j}$ be the truth value ( $\mathrm{T}$ or F) of the option statement $\Omega^{j}$ at state $s_{i}$. The information system for option statements can be represented as shown in Table 1.

Table 1. The information system for option statements

\begin{tabular}{l|l|l|l|l|l}
\hline \multirow{2}{*}{ Universe (U) } & \multicolumn{3}{|l|}{$\begin{array}{l}\text { Condition } \\
\text { attributes }\end{array}$} & Decision attributes (D) \\
\cline { 2 - 6 } & $\Omega^{1}$ & $\Omega^{2}$ & $\ldots$ & $\Omega^{k}$ & $d_{i}$ (the order of ranked states) \\
\hline$s_{1}$ & $a_{11}$ & $a_{12}$ & $\ldots$ & $a_{1 k}$ & $d_{1}$ \\
\hline$s_{2}$ & $a_{21}$ & $a_{22}$ & $\ldots$ & $a_{2 k}$ & $d_{2}$ \\
\hline$\ldots$ & $\ldots$ & $\ldots$ & $\ldots$ & $\ldots$ & $\ldots$ \\
\hline$s_{m}$ & $a_{m 1}$ & $a_{m 2}$ & $\ldots$ & $a_{m k}$ & $d_{\mathrm{m}}$ \\
\hline
\end{tabular}

\section{(2) Calculate the option statement reducts based on rough set theory}

According to Table 1, the option statement reducts can be determined by using attribute reduction methods in rough set theory. Furthermore, ROSETTA, a toolkit for 
analyzing minimal attribute sets within the framework of rough set theory, can be conveniently utilized to obtain the minimal option statement sets. Note that not all option statement reducts are the satisfactory solutions because the order of ranked states by using a statement reduct may be not the same as the preference ranking produced by the initial set of option statements.

\section{(3) Filter the option statement reducts that can generate the same order of ranked states}

One can calculate the order of ranked states for each option statement reduct to check whether the order is equal to the initial one. And only the option statement reducts that do not change the preference ranking results are kept.

Let $\mathrm{D}_{0}$ be the order of ranked states by using the initial set of option statements for a given DM, and $\mathrm{A}_{1}, \mathrm{~A}_{2}, \ldots, \mathrm{A}_{i}$ be the option statement reducts. The procedure for eliminating redundant option statements in option prioritization can be summarized in Fig. 1.

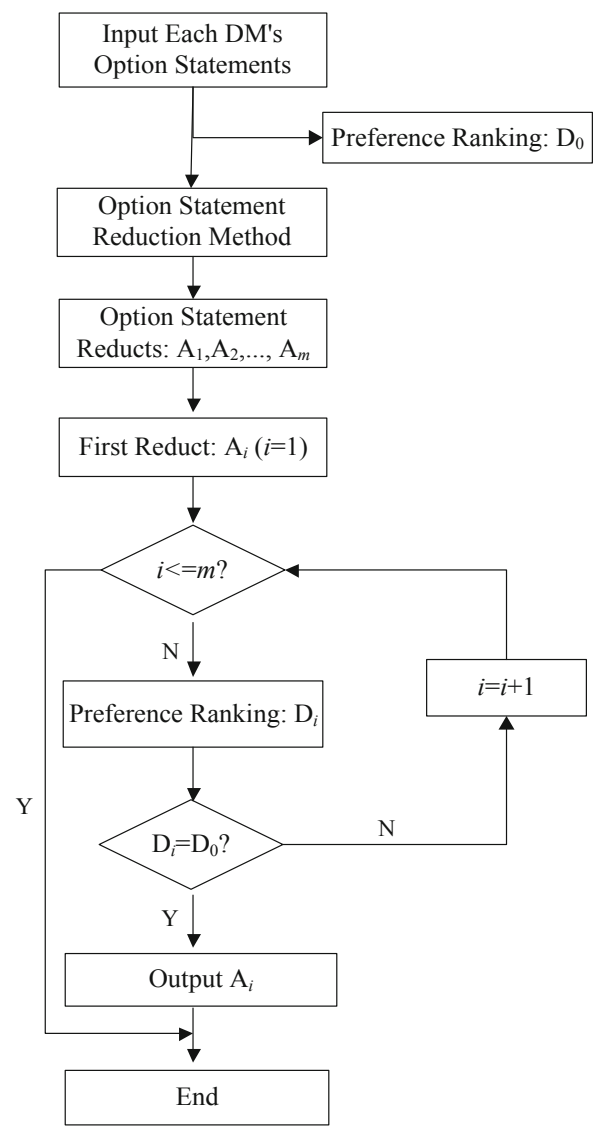

Fig. 1. The algorithm of option statement reduction method 


\section{Case Studies}

A real-world groundwater contamination dispute occurred in Elmira, a small agricultural town in Southern Ontario, Canada, is investigated in this section to show how the proposed option statement reduction method can be applied in reality for eliminating unnecessary or redundant option statements due to individual subjectivity.

Underlying aquifers provided Elmira with safe and fresh drinking water. In 1989, the N-Nitrosodimethylamine (NDMA), a chemical substance which could cause cancer, was discovered in the Elmira's aquifer supplying water by the Ontario Ministry of the Environment (MoE). Uniroyal Chemical Ltd. (UR) was suspected as being the polluter who generated the contamination found in the aquifers. UR was requested to take effective measures for cleaning up the pollutants according to the Ontario's environmental laws (Control Order) issued by MoE [3]. In the Elmira conflict, there are three DMs and five options [21, 22]:

- Ontario Ministry of the Environment (MoE) has one option that whether or not to modify the original Control Order.

- Uniroyal Company (UR) has three options: (1) Delay the negotiations by "dragging its feet"; (2) Accept the current Control Order; (3) Abandon its Elmira plant.

- Local Government (LG) has one option that whether or not to insist on the initial Control Order.

After removing infeasible states, only nine feasible states are left as shown in Table 2.

Table 2. DMs, options and feasible states in the Elmira conflict.

\begin{tabular}{l|l|l|l|l|l|l|l|l|l|l}
\hline DMs & Options & \multicolumn{7}{|l}{ Feasible states } \\
\hline MoE & 1. Modify & N & Y & N & Y & N & Y & N & Y & - \\
\hline UR & 2. Delay & Y & Y & N & N & Y & Y & N & N & - \\
\hline & 3. Accept & N & N & Y & Y & N & N & Y & Y & - \\
\hline & 4. Abandon & $\mathrm{N}$ & $\mathrm{N}$ & $\mathrm{N}$ & $\mathrm{N}$ & $\mathrm{N}$ & $\mathrm{N}$ & $\mathrm{N}$ & $\mathrm{N}$ & $\mathrm{Y}$ \\
\hline LG & 5. Insist & $\mathrm{N}$ & $\mathrm{N}$ & $\mathrm{N}$ & $\mathrm{N}$ & $\mathrm{Y}$ & $\mathrm{Y}$ & $\mathrm{Y}$ & $\mathrm{Y}$ & - \\
\hline
\end{tabular}

In the Elmira conflict, each DM's preference over states can be described by using a set of option statements as given in Tables 3, 4 and 5 . 
Table 3. Option statements and interpretations of $\mathrm{MoE}$

\begin{tabular}{l|l}
\hline $\begin{array}{l}\text { Option } \\
\text { statement }\end{array}$ & Interpretation \\
\hline-4 & MoE does not want UR to abandon its operation in Elmira \\
\hline 3 & MoE wants UR to accept a control order \\
\hline-2 & MoE does not like to see the delay of UR \\
\hline-1 & MoE does not want to modify the original order \\
\hline 5 IFF-1 & $\begin{array}{l}\text { MoE wants LG to insist on the original order if and only if he chooses not to } \\
\text { modify }\end{array}$ \\
\hline
\end{tabular}

Table 4. Option statements and interpretations of UR

\begin{tabular}{l|l}
\hline $\begin{array}{l}\text { Option } \\
\text { statement }\end{array}$ & Interpretation \\
\hline 3 IFF1 & $\begin{array}{l}\text { UR will accept the control order if and only if MoE chooses to modify the } \\
\text { original order }\end{array}$ \\
\hline-4 & UR does not want to abandon its operation in Elmira \\
\hline-5 & UR does not like that LG insist on the original order \\
\hline 2 IFF-5 & $\begin{array}{l}\text { UR would like to delay if and only if LG prefers not to insist on the original } \\
\text { order }\end{array}$ \\
\hline
\end{tabular}

Table 5. Option statements and interpretations of LG

\begin{tabular}{l|l}
\hline Option statement & Interpretation \\
\hline-4 & LG does not want UR to abandon its operation in Elmira \\
\hline-1 & LG prefers that the original control order not be modified \\
\hline $3 \mathrm{IF}-1$ & LG wants UR to accept the original order if MoE does not modify it \\
\hline $5 \mathrm{IF} 1$ & LG would insist on the original order if MoE tends to modify it \\
\hline-2 & LG does not want UR to delay the procedure \\
\hline 5 & LG wants to insist on the original control order \\
\hline
\end{tabular}

By using the option prioritization technique, each DM's preference over states can be determined as follows.

(1) MoE's preference is $s_{7} \succ s_{3} \succ s_{4} \succ s_{8} \succ s_{5} \succ s_{1} \succ s_{2} \succ s_{6} \succ s_{9}$.

(2) UR's preference is $s_{1} \succ s_{4} \succ s_{8} \succ s_{5} \succ s_{9} \succ s_{2} \succ s_{3} \succ s_{7} \succ s_{6}$.

(3) LG's preference is $s_{7} \succ s_{3} \succ s_{5} \succ s_{1} \succ s_{8} \succ s_{6} \succ s_{4} \succ s_{2} \succ s_{9}$.

As shown in Tables 3, 4 and 5, the number of option statements for MoE, UR and LG are 5, 4 and 6, respectively, in which some option statements may be redundant and should be eliminated. The option statement reduction method proposed in Sect. 3 can be employed for removing redundant option statements. 
Firstly, we can calculate MoE's minimal option statement reduct sets. According to Table 3 and MoE's preference, MoE's information system of option statements is expressed as given in Table 6.

Table 6. MoE's information system of option statements

\begin{tabular}{l|l|l|l|l|l|l}
\hline \multirow{2}{*}{ Universe (U) } & \multicolumn{5}{|l|}{ Condition attributes (C) } & Decision attributes (D) \\
\cline { 2 - 7 } & $\mathrm{a} 1=-4$ & $\mathrm{a} 2=3$ & $\mathrm{a} 3=-2$ & $\mathrm{a} 4=-1$ & $\mathrm{a} 5=5 \mathrm{IFF}-1$ & $\begin{array}{l}d_{i} \text { (the order of } \\
\text { ranked states) }\end{array}$ \\
\hline$s_{1}$ & $\mathrm{~T}$ & $\mathrm{~F}$ & $\mathrm{~F}$ & $\mathrm{~T}$ & $\mathrm{~F}$ & 6 \\
\hline$s_{2}$ & $\mathrm{~T}$ & $\mathrm{~F}$ & $\mathrm{~F}$ & $\mathrm{~F}$ & $\mathrm{~T}$ & 7 \\
\hline$s_{3}$ & $\mathrm{~T}$ & $\mathrm{~T}$ & $\mathrm{~T}$ & $\mathrm{~T}$ & $\mathrm{~F}$ & 2 \\
\hline$s_{4}$ & $\mathrm{~T}$ & $\mathrm{~T}$ & $\mathrm{~T}$ & $\mathrm{~F}$ & $\mathrm{~T}$ & 3 \\
\hline$s_{5}$ & $\mathrm{~T}$ & $\mathrm{~F}$ & $\mathrm{~F}$ & $\mathrm{~T}$ & $\mathrm{~T}$ & 5 \\
\hline$s_{6}$ & $\mathrm{~T}$ & $\mathrm{~F}$ & $\mathrm{~F}$ & $\mathrm{~F}$ & $\mathrm{~F}$ & 8 \\
\hline$s_{7}$ & $\mathrm{~T}$ & $\mathrm{~T}$ & $\mathrm{~T}$ & $\mathrm{~T}$ & $\mathrm{~T}$ & 1 \\
\hline$s_{8}$ & $\mathrm{~T}$ & $\mathrm{~T}$ & $\mathrm{~T}$ & $\mathrm{~F}$ & $\mathrm{~F}$ & 4 \\
\hline$s_{9}$ & $\mathrm{~F}$ & $\mathrm{~F}$ & $\mathrm{~T}$ & $\mathrm{~T}$ & $\mathrm{~F}$ & 9 \\
\hline
\end{tabular}

By using the ROSETTA software, the option statement reducts of MoE can be conveniently obtained as illustrated in Fig. 2.

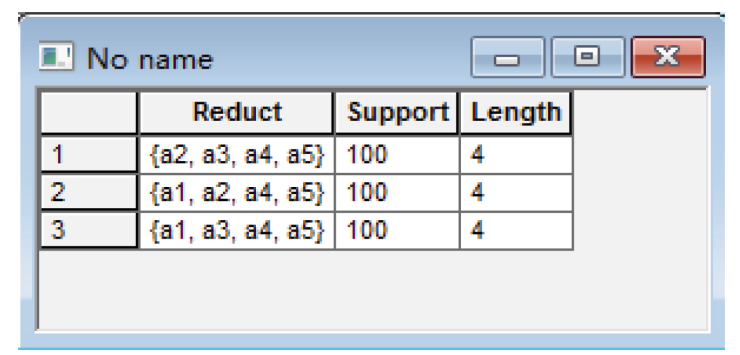

Fig. 2. Option statements reducts for MoE

According to Fig. 2, there are three reducts for MoE's option statements:

(1) $\mathrm{A}_{1}=\{\mathrm{a} 2, \mathrm{a} 3, \mathrm{a} 4, \mathrm{a} 5\}$, which means that the option statement set is $\{3,-2,-1$, $5 \mathrm{IFF}-1\}$.

(2) $\mathrm{A}_{2}=\{\mathrm{a} 1, \mathrm{a} 2, \mathrm{a} 4, \mathrm{a} 5\}$, which means that the option statement set is $\{-4,3,-1$, $5 \mathrm{IFF}-1\}$.

(3) $\mathrm{A}_{3}=\{\mathrm{a} 1, \mathrm{a} 3, \mathrm{a} 4, \mathrm{a} 5\}$, which means that the option statement set is $\{-4,-2,-1$, $5 \mathrm{IFF}-1\}$.

By using GMCR II software [4, 5], the ranking of states for MoE under the aforementioned three reducts can be determined as given in Figs. 3, 4 and 5. 


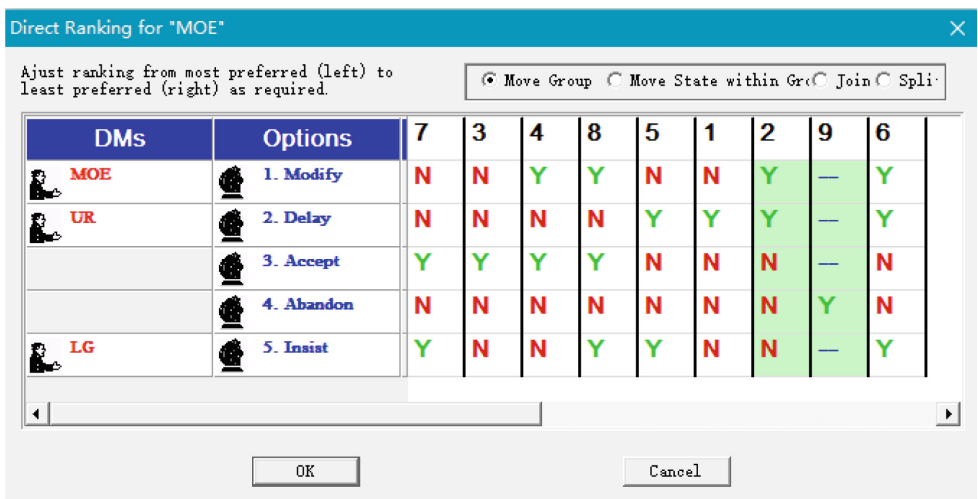

Fig. 3. Ranking of states for $\operatorname{MoE}$ under $\{3,-2,-1,5 \mathrm{IFF}-1\}$

\begin{tabular}{|c|c|c|c|c|c|c|c|c|c|c|c|}
\hline \multicolumn{11}{|c|}{ Direct Ranking for "MOE" } & $\times$ \\
\hline \multicolumn{3}{|c|}{$\begin{array}{l}\text { Ajust ranking from most preferred (left) to } \\
\text { least preferred (right) as required. }\end{array}$} & \multicolumn{9}{|c|}{ (- Move Group $C$ Move State within Gro Join $C$ Spli. } \\
\hline DMs & Options & 7 & 3 & 4 & 8 & 5 & 1 & 2 & 6 & 9 & \\
\hline$s^{\mathrm{MOE}}$ & 1. Modify & $\mathbf{N}$ & N & $\mathrm{Y}$ & $\mathrm{Y}$ & N & N & Y & $\mathbf{Y}$ & - & \\
\hline \multirow[t]{3}{*}{ UR } & 2. Delay & $\mathbf{N}$ & $\mathbf{N}$ & $\mathbf{N}$ & $\mathrm{N}$ & Y & Y & Y & $\mathbf{Y}$ & - & \\
\hline & 3. Accept & $\mathbf{Y}$ & $\mathrm{Y}$ & $\mathrm{Y}$ & Y & $\mathrm{N}$ & $\mathrm{N}$ & N & $\mathbf{N}$ & - & \\
\hline & 4. Abandon & $\mathbf{N}$ & N & N & $N$ & $\mathrm{~N}$ & $N$ & N & $\mathbf{N}$ & $\mathrm{Y}$ & \\
\hline $2^{\text {LG }}$ & 5. Insist & $\mathbf{Y}$ & $\mathbf{N}$ & N & Y & Y & $N$ & $N$ & $\mathbf{Y}$ & - & \\
\hline \multirow[t]{2}{*}{1} & & & & & & & & & & & 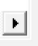 \\
\hline & $\mathrm{OK}$ & & & & & \multicolumn{2}{|c|}{ Cancel } & & & & \\
\hline
\end{tabular}

Fig. 4. Ranking of states for MoE under $\{-4,3,-1,5 \mathrm{IFF}-1\}$

\begin{tabular}{|c|c|c|c|c|c|c|c|c|c|c|c|}
\hline \multicolumn{3}{|c|}{ Direct Ranking for "MOE" } & & & & & & & & & $>$ \\
\hline $\begin{array}{l}\text { Ajust rarking } f_{r} \\
\text { least preferred }\end{array}$ & $\begin{array}{l}\text { ferred (left) } \\
\text { required. }\end{array}$ & & \multicolumn{9}{|c|}{ C Move Group $C$ Move State within Gro Join $C \mathrm{Spli}$} \\
\hline DMs & Options & 7 & 3 & 4 & 8 & 5 & 1 & 2 & 6 & 9 & \\
\hline $6^{\mathrm{MOE}}$ & 1. Modify & $\mathbf{N}$ & $\mathbf{N}$ & Y & Y & $\mathbf{N}$ & $\mathbf{N}$ & Y & Y & - & \\
\hline \multirow[t]{3}{*}{$3^{\text {UR }}$} & 2. Delay & $\mathbf{N}$ & $\mathbf{N}$ & $\mathbf{N}$ & $\mathrm{N}$ & Y & $\mathrm{Y}$ & Y & Y & - & \\
\hline & 3. Accept & $\mathbf{Y}$ & $\mathbf{Y}$ & $\mathrm{Y}$ & Y & $\mathrm{N}$ & $\mathrm{N}$ & $\mathrm{N}$ & $\mathrm{N}$ & - & \\
\hline & 4. Abandon & $\mathbf{N}$ & $\mathbf{N}$ & $\mathrm{N}$ & $\mathrm{N}$ & $\mathrm{N}$ & $N$ & $N$ & $N$ & $Y$ & \\
\hline $2^{\text {LG }}$ & 5. Insist & $\mathbf{Y}$ & $\mathbf{N}$ & $\mathrm{N}$ & $Y$ & $Y$ & $\mathrm{~N}$ & $\mathrm{~N}$ & $Y$ & - & \\
\hline \multirow[t]{2}{*}{11} & & & & & & & & & & & - \\
\hline & $\mathrm{OK}$ & & & & \multicolumn{3}{|c|}{ Cancel } & & & & \\
\hline
\end{tabular}

Fig. 5. Ranking of states for MoE under $\{-4,-2,-1,5 \mathrm{IFF}-1\}$ 
As displayed in Figs. 3, 4 and 5, the rankings of states for $\operatorname{MoE}$ under $\{-4,3,-1$, $5 \mathrm{IFF}-1\}$ and $\{-4,-2,-1,5 \mathrm{IFF}-1\}$ are the same as MoE's initial order of states with the set of option statements being $\{-4,3,-2,-1,5 \mathrm{IFF}-1\}$. Alternatively, $\{-4,3,-1$, $5 \mathrm{IFF}-1\}$ and $\{-4,-2,-1,5 \mathrm{IFF}-1\}$ are the minimal option statement reduct sets of $\{-4,3,-2,-1,5 \mathrm{IFF}-1\}$ for MoE. Similarly, one can continue to calculate the option statement reducts for UR and LG.

By using the Rosetta software, $\{3$ IFF1, $-5,2$ IFF-5 $\}$ is the reduct for UR's option statements $\{3 \mathrm{IFF} 1,-4,-5,2 \mathrm{IFF}-5\}$. And the ranking of states for UR under the option statement reduct is $s_{1} \succ s_{4} \succ s_{8} \sim s_{9} \succ s_{5} \succ s_{2} \succ s_{3} \succ s_{7} \succ s_{6}$, which is not equal to the initial preference of UR. Hence, there are no redundant option statements of UR. For LG's option statements $\{-4,-1,3 \mathrm{IF}-1,5 \mathrm{IF} 1,-2,5\}$, one can find that there are two reducts: $\{-4,-1,-2,5\}$ and $\{-4,3 \mathrm{IF}-1,-2,5\}$. But only the first reduct can generate the preference ranking list which is equal to LG's initial ranking of states. Hence, $\{-4,-1,-2,5\}$ is LG's minimal option statement reduct set, in which the option statements " $3 \mathrm{IF}-1$ " and "5IF1" are redundant and have been removed.

The option statement reduct sets for MoE and LG can be summarized in Table 7.

Table 7. Option statement reduct sets of MoE and LG

\begin{tabular}{l|l|l|l}
\hline DMs & Initial option statement sets & Reduct sets & Redundant statements \\
\hline MoE & $\{-4,3,-2,-1,5 \mathrm{IFF}-1\}$ & $\{-4,3,-1,5 \mathrm{IFF}-1\}$ & -2 \\
\cline { 3 - 5 } & & $\{-4,-2,-1,5 \mathrm{IFF}-1\}$ & 3 \\
\hline LG & $\{-4,-1,3 \mathrm{IF}-1,5 \mathrm{IF} 1,-2,5\}$ & $\{-4,-1,-2,5\}$ & $3 \mathrm{IF}-1,5 \mathrm{IF} 1$ \\
\hline
\end{tabular}

\section{Conclusions and Future Work}

Within the framework of GMCR, a DM's preference over states can be conveniently acquired in terms of a set of option statements, in which some redundant or unnecessary statements may exist and could decrease the computing efficiency of preference ranking. To eliminate these redundant option statements, a novel option statement reduction method is proposed in this paper based on rough set theory by regarding the option statements and the order of ranked states as being condition and decision attributes, respectively. The case study shows that redundant option statements can be effectively removed by using the option statement reduction approach developed in this research.

In the future, the proposed option statement reduction method can be enhanced by using other effective attribute reduction approaches in rough set theory. Moreover, it can be also extended for handling various kinds of preference such as strength of preference, unknown preference and hybrid preference. 


\section{References}

1. Kilgour, D.M., Hipel, K.W., Fang, L.: The graph model for conflicts. Automatica 23, 41-55 (1987)

2. Fang, L., Hipel, K.W., Kilgour, D.M.: Interactive Decision Making: The Graph Model for Conflict Resolution. Wiley, New York (1993)

3. Xu, H., Hipel, K.W., Kilgour, D.M., Fang, L.: Conflict Resolution Using the Graph Model: Strategic Interactions in Competition and Cooperation. Springer, Cham (2018). https://doi. org/10.1007/978-3-319-77670-5

4. Fang, L., Hipel, K.W., Kilgour, D.M., Peng, X.: A decision support system for interactive decision making-part I: model formulation. IEEE Trans. Syst. Man Cybern. Part C (Appl. Rev.) 33(1), 42-55 (2003)

5. Fang, L., Hipel, K.W., Kilgour, D.M., Peng, X.: A decision support system for interactive decision making-part II: analysis and output interpretation. IEEE Trans. Syst. Man Cybern. Part C (Appl. Rev.) 33(1), 56-66 (2003)

6. Hamouda, L., Kilgour, D.M., Hipel, K.W.: Strength of preference in graph models for multiple-decision-maker conflicts. Appl. Math. Comput. 179, 314-327 (2006)

7. Hou, Y., Jiang, Y., Xu, H.: Option prioritization for three-level preference in the graph model for conflict resolution. In: Kamiński, B., Kersten, G.E., Szapiro, T. (eds.) GDN 2015. LNBIP, vol. 218, pp. 269-280. Springer, Cham (2015). https://doi.org/10.1007/978-3-31919515-5_21

8. Yu, J., Pei, L.L.: Investigation of a brownfield conflict considering the strength of preferences. Int. J. Environ. Res. Public Health 15(2), 393 (2018)

9. Li, K.W., Hipel, K.W., Kilgour, D.M., Noakes, D.J.: Integrating uncertain preferences into status quo analysis with application to an environmental conflict. Group Decis. Negot. 14, 461-479 (2005). https://doi.org/10.1007/s10726-005-9003-9

10. Yu, J., Hipel, K.W., Kilgour, D.M., Zhao, M.: Option prioritization for unknown preference. J. Syst. Sci. Syst. Eng. 25, 39-61 (2016). https://doi.org/10.1007/s11518-015-5282-0

11. Bashar, M.A., Hipel, K.W., Kilgour, D.M., Obeidi, A.: Interval fuzzy preferences in the graph model for conflict resolution. Fuzzy Optim. Decis. Making 17, 287-315 (2018). https://doi.org/10.1007/s10700-017-9279-7

12. Bashar, M.A., Obeidi, A., Kilgour, D.M., Hipel, K.: Modeling fuzzy and interval fuzzy preferences within a graph model framework. IEEE Trans. Fuzzy Syst. 24, 765-778 (2016)

13. Bashar, M.A., Kilgour, D.M., Hipel, K.W.: Fuzzy option prioritization for the graph model for conflict resolution. Fuzzy Sets Syst. 26, 34-48 (2014)

14. Wu, N., Xu, Y., Kilgour, D.M.: Water allocation analysis of the Zhanghe River basin using the graph model for conflict resolution with incomplete fuzzy preferences. Sustainability 11, 1099 (2019)

15. Kuang, H., Bashar, M.A., Hipel, K.W., Kilgour, D.M.: Grey-based preference in a graph model for conflict resolution with multiple decision makers. IEEE Trans. Syst. Man Cybern.: Syst. 45, 1254-1267 (2015)

16. Zhao, S., Xu, H.: Grey option prioritization for the graph model for conflict resolution. J. Grey Syst. 29, 14-25 (2017)

17. Rêgo, L.C., dos Santos, A.M.: Probabilistic preferences in the graph model for conflict resolution. IEEE Trans. Syst. Man Cybern.: Syst. 45(4), 595-608 (2015)

18. Rêgo, L.C., dos Santos, A.M.: Upper and lower probabilistic preferences in the graph model for conflict resolution. Int. J. Approximate Reasoning 98, 96-111 (2018)

19. Pawlak, Z.: Rough set theory and its applications to data analysis. Cybern. Syst. 29(7), 661688 (1998) 
20. Yao, Y., Zhao, Y.: Attribute reduction in decision-theoretic rough set models. Inf. Sci. 178 (17), 3356-3373 (2008)

21. Peng, J.: A decision support system for conflict resolution. Ph.D. thesis, University of Waterloo (1999)

22. Bashar, M.A., Kilgour, D.M., Hipel, K.W.: Fuzzy option prioritization for the graph model for conflict resolution. Fuzzy Sets Syst. 246, 34-48 (2014) 